Info Artikel Diterima Mei 2017

Disetujui Agustus 2017

Dipulikasikan April 2018

\title{
KONTRIBUSI TENAGA KERJA "BORONG PRESTASI" \\ PADA PENANGANAN PASCA PANEN KAYU JATI \\ TERHADAP PENDAPATAN KELUARGA \\ (Studi Kasus di TPK Randublatung III Kecamatan Randublatung Kabupaten Blora)
}

\author{
Gadhis Mabruri, Dewi Hastuti, Renan Subantoro \\ Program Studi Agribisnis Fakultas Pertanian \\ Universitas Wahid Hasyim Semarang \\ e-mail : gadhisbiilson@ rocketmail.com
}

\begin{abstract}
The aims of research is to find out the outpouring of hours of labor, the contribution of labor "Borong Prestasi" (TKBP) to the family income and factors affecting labor "Borong Prestasi" income. The basic method used is descriptive method. Respondents are took in stratified random sampling with the number of respondents as many as 52 people. The data used are primary and secondary data. Data collected by interview, observation and recording. Based on analysis of data on average hours TKBP is 5,2 hours per day. TKBP contribution to the family income is 40 percent of TKBP income amounted Rp 595.942 to total family income amounted $\mathrm{Rp}$ 1.486.519. $\mathrm{R}^{2}$ values were obtained using multiple linier regression model for 0,957 means that the independent variable the number of jati wood obtained, the outpouring of hours of labor, length of work and age affecting to TKBP income in post-harvest handling jati wood is 95,7 percent, while 4,3 percent is influenced by other variables outside the model. F test result showed that the number of jati wood obtained, the outpouring of hours of labor, length of work and age together are very significant for TKBP income. T test result showed that the variable of the number of jati wood obtained significant and the outpouring of hours of labor significantly effect for TKBP income, while the variable length of work and age is not significant on TKBP income.
\end{abstract}

Keywords: contribution, jati wood, labor "Borong Prestasi”, Blora Regency.

\section{PENDAHULUAN}

Daerah pedesaan saat ini masih banyak didominasi oleh pekerja di sektor pertanian baik pria maupun wanita. Aktivitas pria sebagai kepala keluarga untuk memperoleh penghasilan pada dasarnya untuk memenuhi kebutuhan keluarga. Kondisi rumah tangga pada lapisan bawah memerlukan sumber penghasilan ganda. Jika hanya dari penghasilan pekerjaan utama tidak mencukupi untuk memenuhi kebutuhan keluarga. Masalah ini mendorong untuk para pria melakukan kerja sambilan untuk memenuhi penghasilan keluarga, serta diharapkan dapat meningkatkan kesejahteraan keluarganya.

Hutan jati Indonesia yang paling luas dikembangkan di Pulau Jawa terutama di daerah Blora yang mempunyai luas hutan hampir 50\% dari wilayahnya. Kawasan Blora adalah perpaduan antara dataran rendah dan 
perbukitan landai dengan ketinggian 20-280 m diatas permukaan laut. Blora bagian selatan merupakan kawasan perbukitan kapur, pohon jati sangat cocok hidup di tanah yang berkapur, seperti Desa Randublatung yang berupa perbukitan kapur, sedangkan Blora bagian utara juga berupa perbukitan kapur. Hal tersebut membuat Blora termasuk daerah penghasil kayu jati dengan kualitas baik di dunia (KPH Randublatung, 2012).

Tabel 1. Produksi Kayu Jati Menurut Kesatuan Pemangkuan Hutan (KPH) di Jawa Tengah Tahun 2013-2014 $\left(\mathrm{m}^{3}\right)$

\begin{tabular}{llll}
\hline \multicolumn{3}{c}{$\begin{array}{c}\text { Kesatuan Pemangkuan Hutan } \\
\text { No. KPH })\end{array}$} & $\begin{array}{l}\text { Tahun } 2013 \\
\text { Tahun 2014 }\end{array}$ \\
\hline 1. & Balapulang & 2.851 & $10.513,60$ \\
2. & Blora & 567 & $7.496,81$ \\
3. & Banyumas Barat & 3.933 & $5.722,89$ \\
4. & Banyumas Timur & 11.891 & 8,76 \\
5. & Cepu & 845 & $28.768,12$ \\
6. & Gundih & 11.016 & $9.532,88$ \\
7. & Kebunharjo & 3.304 & $13.793,03$ \\
8. & Kedu Selatan & 3.019 & 74,99 \\
9. & Kendal & 1.176 & $20.153,98$ \\
10. & Kedu Utara & 2.888 & 5,28 \\
11. & Mantingan & 4.142 & $10.316,47$ \\
12. & Pati & 17.103 & $11.520,11$ \\
13. & Pekalongan Barat & 1.060 & - \\
14. & Pekalongan Timur & 1.505 & - \\
15. & Pemalang & 3.805 & $12.610,09$ \\
16. & Purwodadi & 1.065 & $5.592,70$ \\
$\mathbf{1 7 .}$ & Randublatung & $\mathbf{3 . 2 7 4}$ & $\mathbf{4 5 . 1 6 6 , 9 2}$ \\
18. & Semarang & 371 & $6.234,84$ \\
19. & Surakarta & 5.333 & 400,2 \\
20. & Telawa & 2.351 & $5.013,69$ \\
\hline & Jumlah & $\mathbf{8 1 . 4 9 9}$ & $\mathbf{1 9 2 . 9 2 5 , 5 7}$ \\
\hline
\end{tabular}

Sumber: Jateng.bps.go.id

Berdasarkan data produksi kayu jati di Jawa Tengah pada tahun 20132014 di Desa Randublatung mengalami kenaikan sebesar 41892,92 $\mathrm{m}^{3}$. Besarnya produksi kayu jati di Randublatung, tentunya TPK Randublatung III membutuhkan tenaga kerja untuk kegiatan pasca panennya.

Penelitian ini bertujuan untuk mengetahui curahan jam tenaga kerja, besarnya kontribusi tenaga kerja "Borong Prestasi" (TKBP) terhadap pendapatan keluarga dan faktor-faktor yang mempengaruhi pendapatan tenaga kerja "Borong Prestasi”.

\section{METODE PENELITIAN}

Metode dasar yang digunakan dalam penelitian ini adalah metode deskriptif yaitu teknik analisa yang memberikan informasi hanya mengenai data yang diamati serta menarik kesimpulan yang digeneralisasikan terhadap populasi (Purwanto dan Sulistyastuti, 2011). 


\section{Lokasi Penelitian}

Penelitian dilakukan di TPK Randublatung III Kecamatan Randublatung.

\section{Jenis dan Sumber Data}

Penelitian ini menggunakan data primer dan sekunder.Data primer dikumpulkan dari tenaga kerja sampel melalui wawancara langsung kepada responden dengan menggunakan daftar pertanyaan (kuisioner).Data sekunder dikumpulkan dari lembaga atau instansi seperti Kantor Kecamatan, BPS, dan PT. Perum Perhutani.

\section{Metode Analisis Data}

Tenaga kerja "Borong Prestasi" dalam mencurahkan waktunya untuk kegiatan pasca panen, dapat diketahui menggunakan analisis sederhana dengan persamaan matematika sebagai berikut:

$$
\mathrm{JOK}=\frac{(\mathrm{HKx} \mathrm{JK})}{\mathrm{JKS}}
$$

Keterangan:

$$
\begin{array}{ll}
\text { JOK } & \text { : Jam Orang Kerja } \\
\text { HK } & \text { : Hari kerja } \\
\text { JK } & \text { : Jam kerja } \\
\text { JKS } & \text { : Jam Kerja Standar (jam) }
\end{array}
$$

Menurut Suratyah (2008) jam kerja standar untuk usahatani 7 jam, diluar usahatani 8 jam.

Pengujian Hipotesis pertama dapat menggunakan uji dua pihak atau two tail test.Uji dua fihak digunakan bila hipotesis nol berbunyi "sama dengan 7 jam per hari" dan hipotesis alternatifnya berbunyi "tidak sama dengan 7 jam per hari" dengan menggunakan rumus sebagai berikut:

$$
t=\frac{\bar{x}-\mu_{0}}{\frac{s}{\sqrt{n}}}
$$

Keterangan:

$\mathrm{t} \quad$ : Nilai t yang dihitung, selanjutnya disebut $\mathrm{t}$ hitung

$\bar{x} \quad$ : Rata-rata $\mathrm{X}_{1}$

$\mu_{0}$ : Nilai yang dihipotesiskan

S : Simpangan baku

n : Jumlah anggota sampel

Simpangan baku dapat dicari menggunakan rumus:

$S=\sqrt{\frac{\sum\left(x_{i}-\bar{x}\right)^{2}}{(n-1)}}$

Keterangan:

S : Simpangan baku 


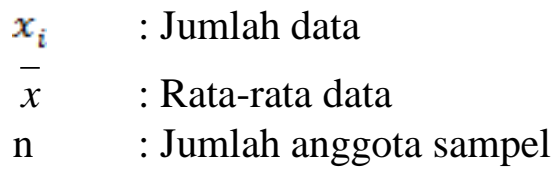

Pengujian hipotesis uji dua pihak ini berlaku ketentuan, bahwa bila harga t hitung berada di daerah penerimaan Ho atau terletak diantara harga tabel, maka Ho diterima dan Ha ditolak. Dengan demikian bila harga t hitung lebih kecil atau sama dengan dari harga tabel maka Ho diterima (Sugiyono, 2007).

Pendapatan tenaga kerja "Borong Prestasi" pada penanganan pasca panen kayu jati yang memberikan kontribusi terhadap pendapatan keluarga.Maka untuk mengetahuinya digunakan analisa perbandingan antara besarnya pendapatan rumah tangga (Rupiah/bulan). Menurut Soekartawi (1995) persamaan matematikanya yaitu:

$$
\text { Kontribusi Pendapatan }=\left(\frac{\text { Pendapatan Tenaga Kerja }}{\text { Pendapatan Total }}\right) \times 100 \%
$$

Faktor yang mempengaruhi pendapatan tenaga kerja borong prestasi yaitu jumlah kayu jati yang diperoleh, curahan jam kerja, maka untuk menghitung faktor-faktor tersebut digunakan regresi linier berganda dengan persamaan sebagai berikut:

$\mathrm{Y}=\mathrm{a}+\mathrm{b}_{1} \mathrm{X}_{1}+\mathrm{b}_{2} \mathrm{X}_{2}+\mathrm{b}_{3} \mathrm{X}_{3}+\mathrm{b}_{4} \mathrm{X}_{4}+\mathrm{b}_{5} \mathrm{D}_{5}+\mathrm{e}$

(Priyatno, 2010).

Keterangan:

Y : Pendapatan tenaga Kerja "Borong Prestasi" (rupiah/bulan)

a : Konstanta

b : Koefisien regresi

$\mathrm{X}_{1}$ : Jumlah kayu jati yang dipanen dan diselesaikan (m3/bulan)

$\mathrm{X}_{2} \quad$ : Jam Kerja (JOK)

$\mathrm{X}_{3} \quad$ : Lamanya bekerja (tahun)

$\mathrm{X}_{4} \quad$ : Umur (tahun)

e : Variabel pengganggu

Pengujian model dengan menggunakan uji statistik dan uji asumsi klasik. Uji asumsi klasik meliputi: normalitas, multikolinieritas, autokorelasi dan heteroskedastisitas. Uji statistik meliputi: uji koefisien determinasi $\left(\mathrm{R}^{2}\right)$, uji $\mathrm{F}$ dan t.

\section{HASIL DAN PEMBAHASAN}

\section{Gambaran Umum Lokasi Penelitian}

Kecamatan Randublatung secara administrasi termasuk dalam Kabupaten Blora. Luas wilayah 211,131 Ha. Kecamatan Randublatung terdiri dari 2 kelurahan dengan jumlah RW sebanyak 91, jumlah RT 399 dan jumlah dusun 102.

Kecamatan Randublatung berada pada ketinggian terendah 44 mdpl dan tertinggi $75 \mathrm{mdpl}$ dengan jarak terjauh dari barat ke timur $16 \mathrm{~km}$ dan jarak terjauh dari utara ke selatan $34 \mathrm{~km}$ (BPS, 2014) 
TPK Randublatung III adalah Tempat Penyimpanan Kayu yang berada di Desa Kalisari Kecamatan Randublatung Kabupaten Blora. TPK sendiri berfungsi untuk menerima, menimbun dan menjual kayu, yang lokasinya berada dalam wilayah pengelolaan Perum Perhutani. Penempatan kayu setelah dikapling ditempatkan di tempat yang sesuai dengan blok-blok yang sudah ada di TPK.

\section{Karakteristik Responden}

1. Umur

Tenaga kerja yang berusia produktif memiliki sifat ketahanan fisik yang lebih baik dibandingkan tenaga kerja yang berusia non produktif. Berikut identitas tenaga kerja "Borong Prestasi" pada penanganan pasca panen kayu jati berdasarkan kelompok umur di TPK Randublatung III dapat dilihat pada Gambar 1.

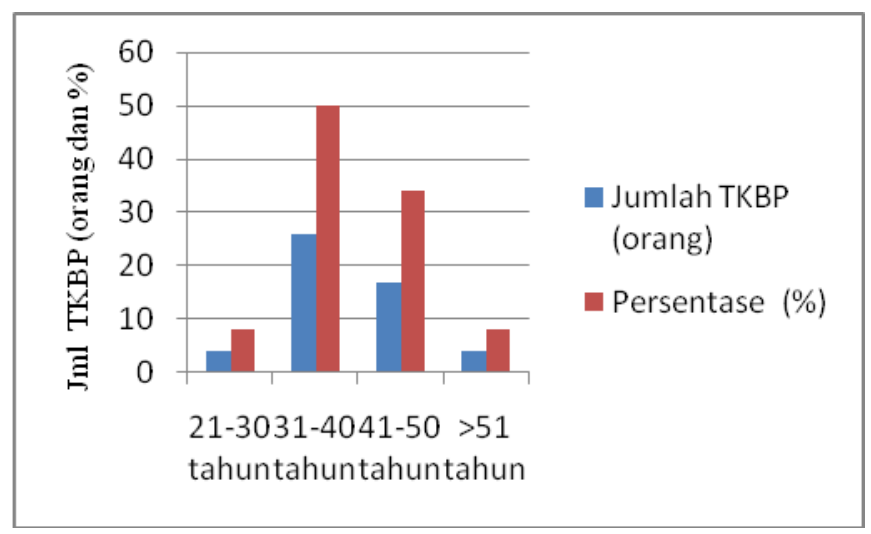

Gambar 1 Grafik Identitas TKBP Berdasarkan Kelompok Umur

Berdasarkan Gambar 1 bahwa umur tenaga kerja "Borong Prestasi" pada penanganan pasca panen umur 31-40 tahun sebanyak 26 orang atau 50 persen, pada umur 41-50 tahun sebanyak 17 orang atau 34 persen, pada umur 21-30 tahun sebanyak 4 orang atau 8 persen dan pada umur $>51$ tahun keatas sebanyak 4 orang atau 8 persen. Pada umur produktif tersebut, produktivitas TKBP pada penanganan pasca panen masih cukup tinggi sehingga lebih potensial dalam menjalankan pekerjaannya. Pada umur produktif kemampuan fisik para TKBP masih memadahi, sehingga memungkinkan dapat menyelesaikan pekerjaan atau jumlah kayu yang dimuat dan dikapling.

2. Lamanya Bekerja

Keberhasilan dalam bekerja tidak hanya ditentukan oleh umur, tetapi juga ditentukan oleh pengalaman dan lamanya bekerja. Pada Gambar 2 dapat dilihat identitas responden tenaga kerja "Borong Prestasi" pada penanganan pasca panen kayu jati berdasarkan lama menekuni pekerjaan. 


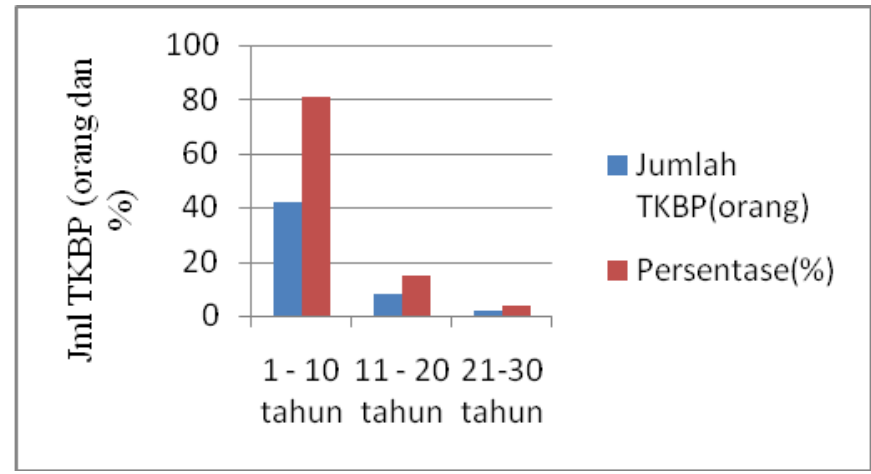

Gambar 2 Grafik Identitas TKBP Berdasarkan Lamanya Bekerja

Sumber: Analisis Data Primer, 2017.

Berdasarkan lamanya bekerja pada Tabel 2 dapat dilihat identitas responden TKBP pada penanganan pasca panen, sebanyak 42 orang atau 81 persen bekerja selama 1-10 tahun, sebanyak 8 orang atau 15 persen bekerja selama 11-20 tahun, sebanyak 2 orang atau 4 persen bekerja selama 21-30 tahun. Berdasarkan lamanya bekerja yang dimiliki oleh TKBP dapat meningkatkan upahnya.

3. Jumlah Anggota Keluarga

Jumlah anggota keluarga akan berpengaruh pada TKBP. Semakin banyak jumlah anggota keluarga, akan menuntut TKBP untuk memenuhi kebutuhannya. Jumlah anggota keluarga terdiri dari bapak, ibu dan anak. Jumlah anggota keluarga TKBP dapat dilihat pada Tabel 2 bahwa responden memiliki jumlah anggota terbanyak yaitu 2 orang sebanyak 19 orang atau 36,5 persen, 3 orang sebanyak 18 orang atau 34,6 persen, 4 orang sebanyak 4 orang atau 7,7 persen, 5 orang sebanyak 10 orang atau 19,2 persen, dan 6 orang sebanyak 1 orang atau 2 persen.

Tabel 2 Jumlah TKBP Berdasarkan Jumlah Anggota Keluarga.

\begin{tabular}{ccc}
\hline Jumlah Anggota & JumlahTKBP (orang) & Persentase(\%) \\
\hline 2 & 19 & 36,5 \\
3 & 18 & 34,6 \\
4 & 4 & 7,7 \\
5 & 10 & 19,2 \\
6 & 1 & 2 \\
\hline Jumlah & 52 & 100 \\
\hline
\end{tabular}

Sumber: Analisis Data Primer, 2017.

4. Pekerjaan selain Sebagai TKBP

Pekerjaan Selain Sebagai TKBP akan berpengaruh pada pendapatan keluarga, dapat dilihat pada Tabel 3 
Tabel 3 Jenis Pekerjaan Selain Sebagai TKBP

\begin{tabular}{clcc}
\hline No. & Jenis Pekerjaan & $\begin{array}{c}\text { Jumlah TKBP } \\
\text { (orang) }\end{array}$ & Persentase(\%) \\
\hline 1. & Buruh Tani & 11 & 21,1 \\
2. & Kuli Bangunan & 5 & 9,7 \\
3. & Tukang Ojek & 5 & 9,7 \\
4. & Pedagang & 4 & 7,6 \\
5. & Memlitur & 4 & 7,6 \\
6. & Serabutan & 23 & 44,3 \\
\hline & Jumlah & 52 & 100 \\
\hline
\end{tabular}

Sumber: Analisis Data Primer, 2017.

Berdasarkan Tabel 3 jenis pekerjaan selain sebagai TKBP dengan jenis pekerjaan buruh tani sebanyak 11 orang atau 21,1 persen, kuli bangunan dan tukang ojek sebanyak 4 orang atau 9,7 persen, pedagang dan memlitur sebanyak 4 orang atau 7,6 persen, serabutan sebanyak 23 orang atau 44,3 persen.

\section{Proses Pelaksanaan Angkutan Ke TPK}

a. Kayu hasil produksi yang telah diberi penandaan dan pencatatan dalam dokumen buku ukur selanjutnya diangkut ke TPK.

b. Mandor pos yang ditunjuk oleh kepala TPK mengarahkan bongkaran angkutan kayu sesuai dengan blok di TPK, dan melakukan verifikasi penerimaan jumlah batang persortimen.

c. Setelah kayu ditempatkan sesuai dengan blok, maka dilakukan pengujian. Pengujian kayu dilakukan oleh seorang penguji. Penguji membuat ringkasan percocokan berupa fisik kayu, jumlah batang per sortimen, mutu dan status.

d. Setelah dilakukan pengujian, Tenaga kerja "Borong Prestasi" mempunyai tugas diantaranya mengkapling dan memuat kayu ke angkutan jika ada pembeli (Perhutani, 2016).

\section{Tarif Upah TKBP}

Sebagai seorang pekerja tentunya mengharapkan timbal balik atau upah dengan apa yang sudah dikorbankan untuk pekerjaan tersebut. Tarif upah tenaga kerja "Borong Prestasi" dapat dilihat pada Tabel 4.

Tabel 4 Tarif Upah TKBP per Hari Pada Penanganan Pasca Panen Kayu Jati, Tahun 2017

\begin{tabular}{ll}
\hline Jenis Pekerjaan Yang Ditangani & $\mathrm{Upah}\left(\mathrm{Rp} / \mathrm{m}^{3}\right)$ \\
\hline Muat & 35.000 \\
Stel Kapling & 35.000 \\
\hline
\end{tabular}

Sumber: Analisis Data Primer, 2017.

\section{Analisis dan Pembahasan}

\section{Hipotesis Pertama}

Hipotesis pertama yaitu diduga curahan jam tenaga kerja "Borong Prestasi" dalam kegiatan penanganan pasca panen kayu jati adalah sebesar 6 
jam/hari. Waktu yang dicurahkan tenaga kerja "Borong Prestasi" pada penanganan pasca panen kayu jati dapat dilihat pada dan Tabel 5.

Tabel 5 Waktu yang Dicurahkan TKBP

\begin{tabular}{ccc}
\hline Jam Kerja (jam/hari) & Jumlah TKBP (orang) & Persentase (\%) \\
\hline $1-5$ & 9 & 22,5 \\
$6-10$ & 31 & 77,5 \\
\hline Jumlah & 40 & 100
\end{tabular}

Sumber: Analisis Data Primer, 2017.

Berdasarkan Tabel 5 waktu yang dicurahkan tenaga kerja "Borong Prestasi" pada penanganan pasca panen terbanyak untuk jam kerja 6-10 jam/hari dengan jumlah 31 orang atau 77,5 persen, dan 1-5 jam/hari dengan jumlah 9 orang atau 22,5 persen. Berdasarkan analisis data diperoleh waktu terendah adalah 1 jam per hari dan tertinggi 9 jam per hari.

Perhitungan angka untuk JK dan HK dikonversikan kedalam bulan terlebih dahulu dan selanjutnya dikonversikan kedalam hari untuk mendapatkan satuan yang sesuai dengan hipotesis pertama.padaTabel 6 dapat dilihat rata-rata jam orang kerja (JOK) yang digunakan TKBP dalam mencurahkan waktunya untuk bekerja pada penanganan pasca panen tanaman jati.

Tabel 6 Rata-rata Jam Orang Kerja (JOK) TKBP

\begin{tabular}{llll}
\hline $\begin{array}{l}\text { Jumlah } \\
\text { Hari/Bulan(HK) }\end{array}$ & $\begin{array}{l}\text { Jumlah } \\
\text { Jam/Bulan } \\
(\mathrm{JK})\end{array}$ & JOK per Bulan & JOK per Hari \\
\hline 17 & 60 & 145,7 & 5,2 \\
\hline
\end{tabular}

Sumber: Analisis data Primer, 2017.

Berdasarkan Tabel 6 dapat dilihat bahwa rata-rata jumlah hari yang digunakan TKBP pada penanganan pasca panen kayu jati adalah 17 hari per bulan dengan jumlah waktu 60 jam per bulan, sehingga rata-rata jam orang kerja TKBP pada penanganan pasca panen kayu jati adalah 145,7 jam per bulan atau 5,2 jam per hari, artinya bahwa TKBP dalam menyelesaikan pekerjaannya membutuhkan waktu 312 menit per hari, dengan jumlah kayu $1 \mathrm{~m}^{3}$ yang terdiri dari 17 batang, dengan penyelesaian pekerjaan 1 batang membutuhkan waktu 18,3 menit.

Hipotesis pertama yang menduga bahwa curahan jam TKBP adalah sebesar 7 jam per hari, ternyata berdasarkan hasil olahan data primer menunjukkan bahwa curahan jam TKBP sebesar 5,2 jam per hari. Untuk membuktikan bahwa hipotesis pertama diterima atau ditolak dapat diuji menggunakan uji dua fihak dengan Ho: $=7$ jam per hari dan Ha: $\neq 7$ jam per hari.

Hasil perhitungan diperoleh simpangan baku sebesar 0.1 , hasil t hitung sebesar 8,72 dan $\mathrm{t}$ tabel 2,010 atau t hitung > t tabel artinya, dalam penelitian ini $\mathrm{Ho}=7$ jam per hari ditolak dan $\mathrm{Ha} \neq 7$ jam per hari diterima, karena TKBP dalam bekerja menghabiskan waktu sebanyak 5,2 jam per hari. 


\section{Hipotesis Kedua}

Hipotesis kedua yaitu diduga tenaga kerja "Borong Prestasi" pada penanganan pasca panen kayu jati memberikan kontribusi lebih dari $30 \%$ terhadap pendapatan keluarga.

Hasil penelitian menunjukkan bahwa pendapatan keluarga diluar TKBP terbesar Rp 1.650 .000 per bulan dengan jumlah TKBP sebanyak 1 orang dan terkecil adalah Rp 250.000 per bulan sebanyak 1 orang, karena dari anggota keluarga tidak ada yang bekerja selain suami. Pendapatan keluarga diluar TKBP dapat dilihat pada Tabel 7.

Tabel 7 Pendapatan Keluarga diluar TKBP

\begin{tabular}{ccc}
\hline No. & Pendapatan Keluarga TKBP $(\mathrm{Rp} / \mathrm{bln})$ & Jumlah TKBP(Orang) \\
\hline 1. & $250.000-550.000$ & 6 \\
2. & $650.000-950.000$ & 31 \\
3. & $1.050 .000-1.450 .00$ & 14 \\
4. & $1.550 .000-1.850 .000$ & 1 \\
\hline & Jumlah & 52
\end{tabular}

Sumber: Analisis Data Primer, 2017.

Berdasarkan hasil analisis dan pembahasan diperoleh rata-rata total pendapatan keluarga dan pendapatan TKBP dapat dilihat pada Tabel 8.

Tabel 8 Rata-rata Kontribusi TKBP Terhadap Pendapatan Keluarga

\begin{tabular}{lll}
\hline $\begin{array}{l}\text { Pendapatan TKBP } \\
\text { (Rp/bulan) }\end{array}$ & Total Pendapatan & Kontribusi \\
& Keluarga (Rp/bulan) & $(\%)$
\end{tabular}

$595.942 \quad 1.486 .519 \quad 40$

Sumber: Analisis data primer 2016.

Berdasarkan hasil penelitian yang sudah dilakukan pendapatan TKBP terbesar Rp 770.000/bulan dan terkecil Rp 350.000/bulan. Jika dilihat dari UMR di Kabupaten Blora tahun 2017 sebesar Rp 1.438.100 untuk pendapatan TKBP dengan rata-rata Rp 595.942 belum sesuai dengan UMR Kabupaten Blora tahun 2017, sedangkan untuk total pendapatan keluarga dengan rata-rata 1.486.519 sudah sesuai dengan UMR Kabupaten Blora tahun 2017. Berdasarkan analisis data diperoleh kontribusi terendah adalah 21 persen dari pendapatan keluarga sebesar Rp 1.650.000 per bulan dan tertinggi sebesar 72 persen dari pendapatan keluarga sebesar Rp 915.000 per bulan. Rata-rata kontribusi TKBP pada penanganan pasca panen terhadap keluarga pada Bulan November 2016 adalah sebesar 40 persen pendapatan TKBP Rp 595.942 terhadap total pendapatan keluarga sebesar Rp 1.486.519, dengan kontribusi diatas rata-rata sebanyak 25 TKBP dan dibawah rata-rata sebanyak 27 TKBP. Menurut Saragih (2001) jika kontribusi diatas 30 persen artinya termasuk pekerjaan utama, namun karena TKBP pada penanganan pasca panen adalah pekerjaan sambilan, artinya kontribusi TKBP terhadap pendapatan keluarga tergolong tinggi, karena TKBP mempunyai pekerjaan selain di penanganan pasca panen. Hipotesis kedua terbukti bahwa kontribusi TKBP Pada penanganan pasca panen lebih dari 30\%. 


\section{Hipotesis Ketiga}

Hipotesis ketiga yaitu diduga faktor yang mempengaruhi pendapatanTKBPjumlah kayu jati yang diperoleh, curahan jam kerja, lamanya bekerja dan umur menggunakan analisis regresi linier berganda.

Tabel 9 Hasil Analisis Regresi Faktor-faktor yang mempengaruhi Pendapatan TKBP Penanganan Pasca Panen Kayu Jati.

\begin{tabular}{lllll}
\hline No. & Variabel & Koefisien & T hitung & Sig. \\
\hline 1. & Konstanta & 83573,630 & 2,340 & 0,024 \\
2. & Jumlah kayu & 21599,932 & 6,983 & $0,000^{* *}$ \\
3. & Jam kerja & 1967,962 & 3,633 & $0,001^{*}$ \\
4. & Lamanya bekerja & $-511,114$ & $-0,571$ & 0,571 \\
5. & Umur & 63,711 & 0,986 & 0,329 \\
6. & Koefisien determinasi $\left(\mathrm{R}^{2}\right)$ & 0,957 & & \\
7. & F hitung & 262,314 & & $0,000^{* *}$ \\
8. & F tabel 1 \% & 4,22 & & \\
9. & T tabel 5 \% & 2,012 & & \\
10. & Durbin Watson & 1,710 & & \\
\hline
\end{tabular}

Keterangan:

**Sangat signifikan pada tingkat kepercayaan 99\% $(\alpha=0,01)$.

*Signifikan pada tingkat kepercayaan $95 \%(\alpha=0,05)$.

Sumber: Hasil Output Data SPSS, 2017.

Berdasarkan hasil analisis regresi linier berganda pada Tabel 10 menunjukkan pendapatan TKBP pada penanganan pasca panen dapat diformulasikan dalam model sebagai berikut:

$\mathrm{Y}=83573,630+21599,932 \mathrm{X}_{1}+1967,962 \mathrm{X}_{2}-511,114 \mathrm{X}_{3}+63,711 \mathrm{X}_{4}+\mathrm{e}$

Hasil pengujian menunjukkan bahwa variabel terbebas dari uji asumsi klasik meliputi uji normalitas, multikolinieritas, heteroskedastisitas dan autokorelasi sehingga model layak digunakan dalam penelitian.

\section{Uji Statistik}

a. Uji Koefisien Determinasi $\left(\mathrm{R}^{2}\right)$

Uji koefisien determinasi $\left(\mathrm{R}^{2}\right)$ digunakan untuk melihat seberapa besar jumlah kayu yang diperoleh, jam kerja, lamanya bekerja dan umur dapat menjelaskan pengaruhnya terhadap besarnya upah TKBP pada penanganan pasca panen tanaman jati.

Tabel 10 Hasil Adjusted R Square Pada Model Regresi

Model Summaryb

\begin{tabular}{|r|r|r|r|r|r|}
\hline Model & \multicolumn{1}{|c|}{$\mathrm{R}$} & \multicolumn{1}{c|}{ R Square } & \multicolumn{1}{c|}{$\begin{array}{c}\text { Adjusted } \mathrm{R} \\
\text { Square }\end{array}$} & $\begin{array}{c}\text { Std. Error of the } \\
\text { Estimate }\end{array}$ & Durbin-Watson \\
\hline 1 & .978 & .957 & .953 & 23352.217 & 1.710 \\
\hline
\end{tabular}

a. Predictors: (Constant), UMUR, JML.KAYU, LAMANYA, CURAHAN

b. Dependent Variable: PNDPTN

Sumber: Hasil Output Data SPSS, 2017. 
Berdasarkan Tabel 11 didapat nilai Adjusted R Square adalah sebesar 0,957 menunjukkan bahwa proporsi pengaruh variabel bebasterhadap variabel terikat (upah) sebesar 95,7\%. Artinya jumlah kayu yang diperoleh, jam kerja, lamanya bekerja, dan umur memiliki proporsi pengaruh terhadap pendapatan sebesar $95,7 \%$ sedangkan sisanya 4,3\% dipengaruhi oleh variabel lain yang tidak ada dalam penelitian ini.

b. Uji F-Statistik

Uji F-Statistik digunakan untuk menguji pengaruh variabel independen secara bersama-sama terhadap variabel dependen. Hasil uji $\mathrm{F}$ dapat dilihat pada Tabel 11, sebagai berikut:

Tabel 11 Pengujian F-Statistik

ANOVA $^{b}$

\begin{tabular}{|ll|r|r|r|r|r|}
\hline Model & & Sum of Squares & Df & Mean Square & F & \multicolumn{1}{c|}{ Sig. } \\
\hline 1 & Regression & $5.722 \mathrm{E} 11$ & 4 & $1.430 \mathrm{E} 11$ & 262.314 & $.000^{\mathrm{a}}$ \\
& Residual & $2.563 \mathrm{E} 10$ & 47 & $5.453 \mathrm{E} 8$ & & \\
& Total & $5.978 \mathrm{E} 11$ & 51 & & & \\
\hline
\end{tabular}

Nilai probability $\mathrm{F}$ hitung (pada kolom sig.) pada Tabel 12, didapat nilainya 0,000 artinya $<0,01$ sehingga dapat disimpulkan bahwa jumlah kayu jati yang diperoleh, curahan jam kerja, lamanya bekerja dan umur secara bersamasama berpengaruh sangat nyata terhadap pendapatan TKBP.

c. Uji t-Statistik

Uji t-statistik digunakan untuk menguji seberapa jauh pengaruh variabel bebas secara individual dalam mempengaruhi variabel terikat.

Tabel 12 Hasil Uji t-Statistik

Coefficients $^{a}$

\begin{tabular}{|c|c|c|c|c|c|c|}
\hline \multirow{2}{*}{\multicolumn{2}{|c|}{ Model }} & \multicolumn{2}{|c|}{ Unstandardized Coefficients } & \multirow{2}{*}{$\begin{array}{c}\begin{array}{c}\text { Standardized } \\
\text { Coefficients }\end{array} \\
\text { Beta }\end{array}$} & \multirow[b]{2}{*}{$\mathrm{T}$} & \multirow[b]{2}{*}{ Sig. } \\
\hline & & B & Std. Error & & & \\
\hline \multirow[t]{5}{*}{1} & (Constant) & 83573.630 & 35707.665 & & 2.340 & .024 \\
\hline & JML.KAYU & 21599.932 & 3093.397 & .644 & 6.983 & .000 \\
\hline & CURAHAN & 1967.962 & 541.706 & .342 & 3.633 & .001 \\
\hline & LAMANYA & -511.114 & 895.474 & -.024 & -.571 & .571 \\
\hline & UMUR & 643.711 & 652.805 & .043 & .986 & .329 \\
\hline
\end{tabular}

a. Dependent Variable: PNDPTN

Sumber: Hasil Output Data SPSS, 2017.

1. Jumlah Kayu yang Diperoleh

Berdasarkan hasil pengolahan data diperoleh t hitung 6,983 lebih besar daripada t tabel $\alpha=1 \%(2,685)$ dengan nilai signifikasi 0,000 . Oleh karena $t$ hitung $>\mathrm{t}$ tabel maka, pada taraf $\alpha=1 \%$ variabel jumlah kayu memberi pengaruh sangat signifikan terhadap pendapatan pada tingkat kepercayaan 99\%. Artinya, jika jumlah kayu ditingkatkan sebesar $1 \mathrm{~m}^{3}$, maka pendapatan 
TKBP akan meningkat sebesar Rp 21.599,932, sehingga Ho ditolak dan Ha diterima. Disimpulkan bahwa hipotesis ketiga yang menyatakan bahwa faktor yang mempengaruhi pendapatan adalah jumlah kayu yang diperoleh, terbukti kebenarannya.

Variabel jumlah kayu yang diperoleh berpengaruh sangat nyata terhadap pendapatan TKBP pada penanganan pasca panen disebabkan tarif upah berdasarkan jumlah kayu jati yang diperoleh.

2. Jam Kerja

Berdasarkan hasil pengolahan data diperoleh t hitung 3,633 lebih besar daripada t tabel $\alpha=5 \%(2,012)$ dengan nilai signifikasi sebesar 0,001 . Oleh karena $\mathrm{t}$ hitung $>\mathrm{t}$ tabel maka, pada taraf $\alpha=5 \%$, variabel jam kerja memberi pengaruh yang signifikan terhadap pendapatan, pada tingkat kepercayaan 95\%, artinya jika curahan jam kerja ditingkatkan sebesar 18,3 menit/hari, maka pendapatan TKBP akan meningkat sebesar Rp. 1.967.962, sehingga Ha diterima dan Ho ditolak. Disimpulkan, hipotesis ketiga terbukti kebenarannya karena ternyata jumlah curahan jam kerja termasuk faktor yang mempengaruhi pendapatan TKBP.

Variabel jam kerja secara statistik berpengaruh nyata terhadap pendapatan TKBP pada penanganan pasca panen kayu jati, disebabkan responden dalam melakukan pekerjaan sesuai kemampuan fisik yang dimiliki, artinya semakin tinggi upah TKBP dalam menangani pekerjaan tentunya akan berdampak pada waktu dengan curahan yang lebih tinggi.

3. Lamanya Bekerja

Berdasarkan hasil pengolahan data diperoleh $\mathrm{t}$ hitung -0,571 lebih kecil daripada t tabel $\alpha=5 \%(2,012)$ dengan nilai signifikasi sebesar 0,571 . Oleh karena $\mathrm{t}$ hitung $<\mathrm{t}$ tabel maka, pada taraf $\alpha=5 \%$, variabel lamanya bekerja berpengaruh tidak nyata terhadap pendapatan, pada tingkat kepercayaan 95\% sehingga Ho diterima dan Ha ditolak. Disimpulkan, hipotesis ketiga tidak terbukti kebenarannya.

Variabel lamanya bekerja secara statistik berpengaruh tidak nyata terhadap pendapatan TKBP pada penanganan pasca panen kayu jati, disebabkan lamanya bekerja tidak menentukan seberapa besar kayu yang diperoleh dan lamanya bekerja tidak digunakan sebagai dasar penentuan upah.Karena, jika seorang TKBP tidak bekerja pada hari tebangan, maka jumlah kayu jati yang diperoleh setiap bulannya kecil meskipun dia sudah lama bekerja sebagai TKBP.

4. Umur

Berdasarkan hasil pengolahan data diperoleh t hitung 0,986 lebih kecil daripada $\mathrm{t}$ tabel $\alpha=5 \%(2,012)$ dengan nilai signifikasi sebesar 0,329 . Oleh karena $\mathrm{t}$ hitung $<\mathrm{t}$ tabel maka, pada taraf $\alpha=5 \%$ variabel umur berpengaruh tidak nyata terhadap pendapatan, pada tingkat kepercayaan $95 \%$ sehingga Ho diterima dan Ha ditolak. Disimpulkan, hipotesis ketiga tidak terbukti kebenarannya.

Variabel umur secara statistik berpengaruh tidak nyata terhadap pendapatan TKBP pada penanganan pasca panen kayu jati, disebabkan dalam kegiatan mengkapling dan memuat kayu tidak membedakan umur baik tua 
maupun muda tetapi dilihat dari kekuatan fisik seberapa mampu TKBP melakukan pekerjaan di TPK.

\section{KESIMPULAN}

Berdasarkan hasil penelitian dan analisis yang telah dilakukan, maka diperoleh kesimpulan sebagai berikut:

1. Curahan jam tenaga kerja "Borong Prestasi" pada penanganan pasca panen yaitu sebesar 5,2 jam per hari.

2. Kontribusi tenaga kerja "Borong Prestasi" pada penanganan pasca panen terhadap pendapatan keluarga sebesar 40 persen dari rata-rata pendapatan TKBP sebesar Rp 595.942 terhadap pendapatan total keluarga Rp 1.486 .519 per bulan.

3. Faktor-faktor yang mempengaruhi pendapatan tenaga kerja "Borong Prestasi" pada penanganan pasca panen nilai $\mathrm{R}^{2}$ yang diperoleh sebesar 0,957 artinya variabel bebas (jumlah kayu jati yang diperoleh, curahan jam kerja, lamanya bekerja, dan umur) mempengaruhi pendapatan TKBP pada penanganan pasca panen kayu jati sebesar 95,7 persen, sementara 4,3 persen dipengaruhi oleh variabel lain diluar model. Pada uji F-Statistik yaitu jumlah kayu jati yang diperoleh, curahan jam kerja, lamanya bekerja, dan umur secara bersama-sama berpengaruh sangat nyata terhadap pendapatan TKBP. Pada uji t-statistik variabel jumlah kayu yang diperoleh berpengaruh sangat nyata dan curahan jam kerja berpengaruh nyata, sedangkan lamanya bekerja dan umur berpengaruh tidak nyata terhadap pendapatan TKBP.

\section{DAFTAR PUSTAKA}

Badan Pusat Statistik Jawa Tengah. (2014). Produksi Kayu Jati Menurut Kesatuan Pemangkuan Hutan Tahun 2013-2014 $\left(\mathrm{m}^{3}\right)$. Retrived September 29, 2016, from www.jateng.bps.go.id.

Badan Pusat Statistik Kabupaten Blora. (2014). Kecamatan Randublatung Dalam Angka.Retrived October 2, 2016, from www.blorakab.bps.go.id.

KPH Randublatung.(2012). Profil Perum Perhutani KPH Randublatung.Retrived October 2, 2016, from http://kesatuanpemangkuanhutanrandublatung.com.

Perhutani.(2016). Prosedur Kerja.Jakarta: Perhutani.

Priyatno, Duwi. (2010). Teknik Mudah Melakukan Analisis Data Penelitian dengan SPSS. Yogyakarta: Gava Media.

Purwanto, Erwan Agus dan Dyah Ratih S. (2011).Metode Penelitian Kualitatif Untuk Administrasi Publik dan Masalah-masalah Sosial. Yogyakarta: Gava Media. 
Saragih, Bungaran. (2001). Pengembangan agribisnis Dalam Pembangunan Nasional Menghadapi Abad ke-21.http://Pengembangan SistemAgribisnis.

Soekartawi. (1995). Ilmu Usaha Tani Jakarta: Raja Grafindo Persada.

Sugiyono.(2001). Metode Penelitian Administrasi. Bandung: Alfabeta.

Suratiyah.(2008). Ilmu Usahatani.Jakarta: Penebar Swadaya. 